\title{
DESIGN AND ANALYSIS OF DUMP BODY ON THREE WHEELED AuTO VEHICLE
}

\author{
${ }^{1}$ K.Radhakrishna, ${ }^{2}$ S. Srinivasa Rao and ${ }^{3}$ B.Sudhakara Rao \\ ${ }^{1}$ Assistant professor, Department of Mechanical engineering, KLUniversity, Vijayawada, \\ AP \\ 2 professor, Department of Mechanical engineering, KLUniversity, Vijayawada, AP \\ ${ }^{3}$ Assistant professor, Department of Mechanical engineering, KLUniversity, Vijayawada, \\ AP
}

\begin{abstract}
In developed areas, garbage is increasing day by day to reduce the garbage, Indian automobile industries are manufacturing different types of truck bodies. These truck bodies having large fuel consumption due to the heavy weight of truck and bulk in size. It is difficult to travel narrow streets and easily fail due to corrosion while contact with wet garbage and also manual interference is needed for loading and unloading of garbage. Three wheeled auto rickshaw is best suited to reduce this type of problem. The three wheeled auto rickshaw is a small vehicle which is ideal for short, narrow roads as well as highway hauls for small bulky superior loads. Dump body on three wheeled auto rickshaw is mainly desirable to pick up the smaller quantities of wastage and hand it over to the land filler and other recycling or other treatment facilities. The main purpose of this tree wheeled dump body is to reduce the manpower. In the present work an attempt is made to design three wheeled dump body with a capacity of $750 \mathrm{~kg}$ payload. Generally the under frame of the body is assembled first, then the base sheet side walls front and rear sheet with stiffeners are assembled in order to complete the assembly and it's done by using PRO/E 4.0 CAD software. The designed three wheeled dump body has been analyzed for stress using the finite technique in addition to payload weight of garbage as being considered to reduce fuel consumption and cost of manufacturing two types of materials are used one is the aluminum another one is mild steel which used supporting component in dump body. After analyzing best body is found.
\end{abstract}

\section{KEYWORDS}

Deformation, Stress intensity, Von-Misses stresses, payload.

\section{INTRODUCTION}

In many city municipalities' garbage is handled by using rickshaws, tractors and Lorries are used for so many years. There is unloading facility is not available in rickshaws. Garbage trucks [1] are not passing into the small streets due to bulk in size. For that a small capacity body with the required space for traveling on streets and capable of handle the one tone of garbage is required. Reduce human interference for unloading the garbage form these trucks is only possible with dump bodies, unloading the garbage with tilting to rear by hydraulic system. Three wheeled vehicles is best suited for travel in narrow streets and total weight of the vehicle is less as compared with garbage trucks and which can also suited for handling the different type of materials. Which having less space occupied and handle at least $750 \mathrm{Kg}$ of material. If we arranged hydraulic seal system to three wheeled vehicles the dump body can easily tilt to rear and height of the body is also less as compared to other trucks while tilting operation. 
International Journal on Cybernetics \& Informatics (IJCI) Vol. 4, No. 2, April 2015

One body with suitable shape to unloading the garbage and avoid corrosion properties while handling wet garbage. It is better to provide the drain system to minimize the foul smell coming from the garbage during loading and unloading conditions. Such body is mounted on a three wheeler vehicle. It should be a convent for loading and unloading the garbage. The cost of transport is less compared to heavy dump body and it is moving faster than rickshaw. In a short time more area will be covered firm, collected and unloading the garbage. This type of model in used in olden days to carry the materials like sand etc.

\subsection{Problem Definition}

[3] Garbage is increasing day by day. To reduce the garbage in city areas, industries are manufacturing the different type of truck bodies like garbage Lorries, Tractors etc. Manual interference is needed for loading and unloading the garbage from above specified truck bodies. These truck bodies are not suitable to transport in narrow streets or small, place streets due to it having a bulk in size. These truck bodies are having large fuel consumption due to the heavy weight of the truck. These bodies are easily failure due to corrosion properties. While the material contact with the wet garbage. It has an open top due to which the smell is coming while traveling in bad road condition; cost is also high for the heavier bodies.

\section{DESIGN OF THREe WheELED Auto DUMP BODY}

\subsection{The General requirements to design the body[2]}

- Overall dimensions: The overall dimensions of the load body shall comply be as per recommendations provided by the vehicle manufacturers.

- The capacity of the Auto Remover is 1.0 cubic meters

- The dumping height from the ground is $1000 \mathrm{~mm}$

- The width of the dumping body is $1448 \mathrm{~mm}$

- The length of the dumping body is $1762.9 \mathrm{~mm}$

\subsection{Body construction requirements}

In constructing [4] the body or load platform, all practicable steps shall be taken to keep the centre of gravity of the vehicle as low as possible.

- The construction [5] of the body or load platform shall be such as not to impair the soundness and functioning of the wiring and braking circuits.

- The load body shall be constructed over a sub-frame to distribute the load evenly on the chassis frame and also to create gaps between body and tire / chassis for wheel articulation.

- The material used for sub-frame construction shall be steel or aluminum alloy or any composite material with adequate strength to bear impact loads and the table1 shows the allowable stress of aluminium and Mild steel.

- The floor, headboard (also called crash guard or front wall) and side walls is the main load bearing elements of the body. The side walls and crash guard shall be constructed to bear a part of the load carried on the vehicle in case of braking, turning, travel on slopes etc. as given below, which can also be proved by FEM analysis.

- Side walls : $15 \%$ of load carried

- Crash guard or head board : $100 \%$ of load carried

$\circ$ Rear wall or tail gate : $15 \%$ of load carried 
By taking the above considerations into account, the diagram of the dump body is shown in figure 1 .

Table1. Allowable Stresses Of Mild Steel And Aluminum

\begin{tabular}{|c|c|}
\hline MATERIALS & $\begin{array}{c}\text { ALLOWABLE } \\
\text { STRESS } \\
\text { (Mpa) }\end{array}$ \\
\hline $\begin{array}{c}\text { MILD } \\
\text { STEEL }\end{array}$ & 380 \\
\hline ALUMINUM & 350 \\
\hline
\end{tabular}

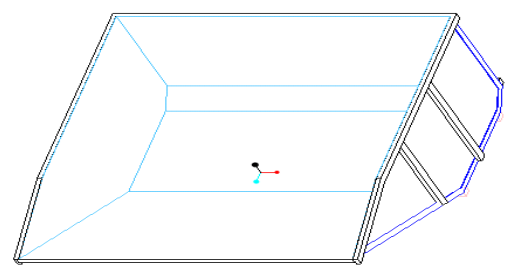

Figure 1. Model Of The Dump Body

\subsection{Important Terms In Design Of Three Wheeled Dump Body}

- GROSS VEHICLE WEIGHT

It means technically permissible maximum weight declared by the manufacturer of the vehicle.

- GROSS COMBINED VEHICLE WEIGHT

It means the total weight of the truck and trailer or tractor and trailer or semitrailer with payload.

- WEIGHT DISTRIBUTION ON DUMP BODY

It means the distribution of the body and payload and the relationship with respect to the permissible load on the axles.

- CUBIC CAPACITY It means the usable internal load carrying space as related to

Closed bodies, van trailers, bulk trailers, tank trailers, containers etc.

- PAY LOAD (P) Maximum permitted mass of payload. The Pay load is calculated by subtracting the tare mass from rating.

The figure 2 represents the dimensions of dump body given below.

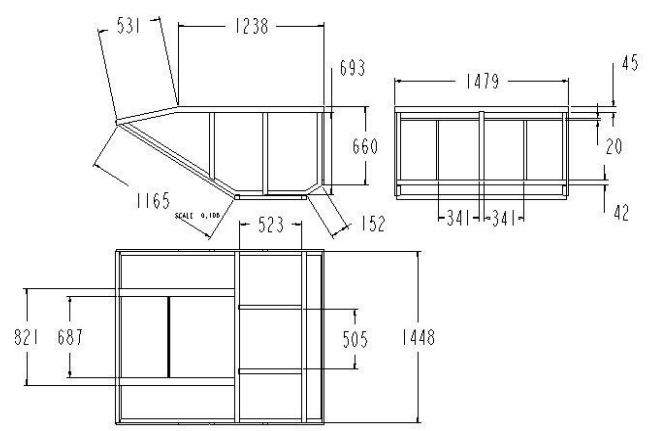

Figure 2. Dimensions of dump body

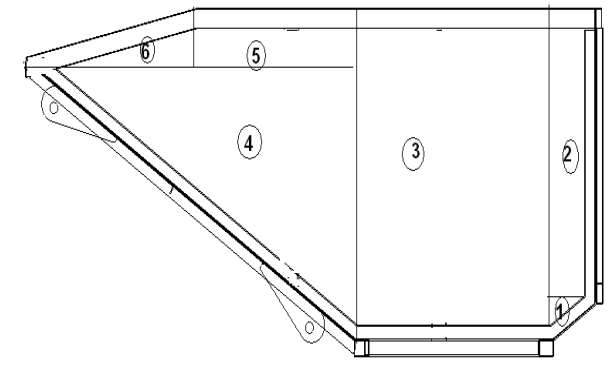

Figure 3. Volumes of dump body 


\subsection{Volume Of Three Wheeled Dump Body}

Figure 3 represents the total volume of the body divided into 6 numbers of volumes

Volume 1 is the triangle

Volume $1=1 / 2$ X 35.1X 117 X1447. $8=2972840.13$ X 10-9=2.99 X10-3 m3

Volume 2 is the rectangle

Volume $2=661.4$ X 35.1 X $1447.8=33610879.7$ X 10-9 = $0.0336 \mathrm{~m} 3$

Volume 3 is the rectangle

Volume $3=623.4$ X 740.76 X $1447.8=668579249.3 \times 10-9=0.6685 \mathrm{~m} 3$

Volume 4 is the triangle

Volume $4=1 / 2$ X 989.33 X631.26 X $1447.8=452093253.6$ X 10-9 = $0.452 \mathrm{~m} 3$

Volume 5 is the triangle

Volume $5=459.38$ X109.501 X1447.8 $=72828059.95 \times 10-9=0.0728 \mathrm{~m} 3$

Volume 6 is the triangle

Volume $6=1 / 2$ X $520.95 \times 109.501 \times 1447.8=41294546.81 \times 10-9=0.04129 \mathrm{~m} 3$

Total volume of the body $=2.99 \times 10-3+0.0336+0.6685+0.452+0.0728+0.0412=1.27 \mathrm{~m}^{3}$

Total volume of the body $=1.27109 \mathrm{~m} 3$

\section{Structural ANalysis Of Three WheEled Dump Body}

\subsection{Geometry model of three wheeled dump body}

The analysis is being done in ANSYS 11.0 Workbench from Figure 4. The first step is to attach the geometry. Before attaching the geometry to ANSYS workbench it specified several options that determine the characteristics of the geometry you choose to import from PRO/E 4.0. These options are: solid body parameters, attributes, named selections, material properties; Analysis Type (2-D or 3-D), allowing CAD associatively, importing coordinate systems, saving the updated CAD file in reader mode, "smart" refreshing of models with unmodified components, importing large models via a temporary file, and allowing parts of mixed dimension to be imported as assembly components that have parts of different dimensions. The availability of these options varies across the supported CAD systems. In performing the design and analysis of the model, two softwares are used. PRO/E is used for modeling the model. This model is transferred to Ansys workbench and meshing of the model is done using Ansys workbench. From Ansys workbench the meshed model is exported to Ansys to perform analysis in Ansys, table 2 gives various material properties of the dump body. So in this chapter we discuss some important features of these softwares. In this present attempt, I took two types of materials and designed three types of three wheeled dump bodies.

Table 2. Type Of Material Properties

\begin{tabular}{|c|c|c|c|}
\hline $\begin{array}{l}\text { MATERIAL } \\
\text { USED }\end{array}$ & $\begin{array}{c}\text { YOUNG'S } \\
\text { MODULUS } \\
\text { MPa }\end{array}$ & $\begin{array}{c}\text { POISSION'S } \\
\text { RATIO }\end{array}$ & $\begin{array}{c}\text { DENSITY } \\
\mathrm{kg} / \mathrm{mm}^{3}\end{array}$ \\
\hline MILD STEEL & $2.1 \mathrm{e}+005$ & 0.25 & $7.85 \mathrm{e}-006$ \\
\hline $\begin{array}{l}\text { ALUMINIMUM } \\
\text { ALLOY }\end{array}$ & 71000 & 0.33 & $2.77 \mathrm{e}-006$ \\
\hline
\end{tabular}

Define Connections:

In ANSYS workbench, when an assembly is imported from a PRO/E 4.0 as an IGES format contact between various parts is automatically detected. The assembly components are in 
connected to each other to form into a complete assembly with an element and nodes thus forming into a perfect assembly.

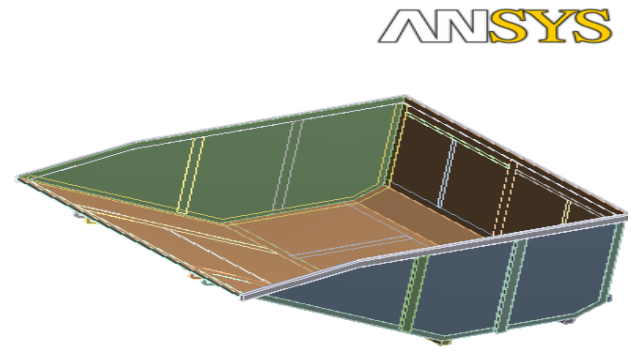

Figure 4. Geometry of dump body

\subsection{Apply mesh controls}

Figure 5 represents the meshing of the given dump body is done with the tetrahedron element type of mesh, table 3 shows finite element details of tetrahedron in different methods [6]. The element is defined by 10 nodes having three degrees of freedom at each node: translations in the nodal $\mathrm{x}, \mathrm{y}$, and $\mathrm{z}$ directions. The element has plasticity, hyper elasticity, creep, stress stiffening, large deflection, and large strain capabilities. It also has the mixed formulation capability for simulating deformations of nearly incompressible elastic-plastic materials, and fully incompressible hyper elastic materials.

Table 3. Finite Element Details

\begin{tabular}{|l|l|}
\hline \multicolumn{1}{|c|}{ Method } & Tetrahedrons \\
\hline Element size & 80 \\
\hline Nodes & 80170 \\
\hline Elements & 40062 \\
\hline
\end{tabular}

\section{ANISYYS}

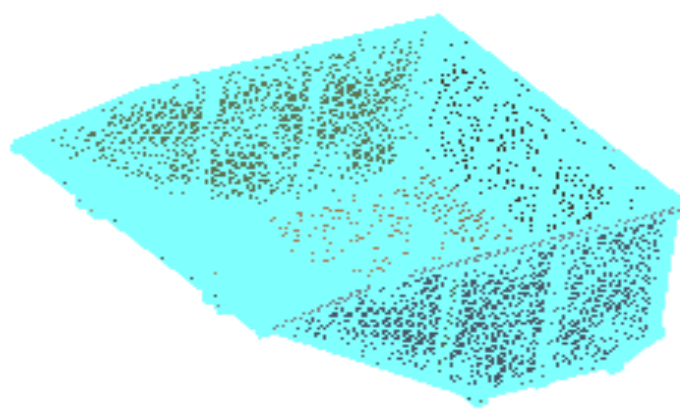

Figure 5: Meshing of the dump body

\subsection{Loading conditions}

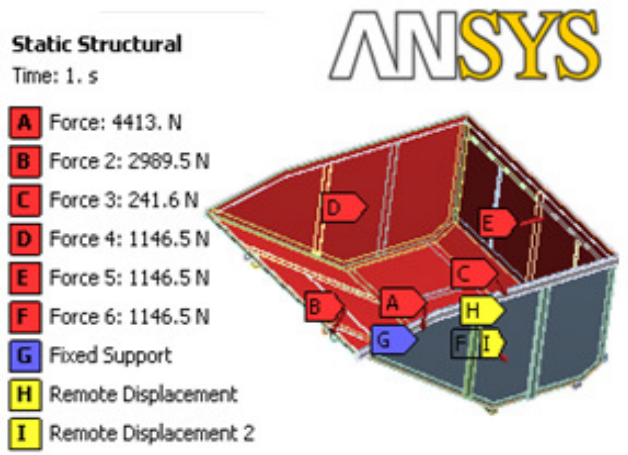

Figure 6: Various Forces acting on the dump body 
Figure 6 represents the following loads and load combinations [8] are considered for analysis

Total weight at bottom (platform) $=$ total mass of material used $\mathrm{X}$ acceleration due to gravity

$$
\begin{aligned}
& =450 \times 9.8066 \\
= & 4413 \mathrm{~N}
\end{aligned}
$$

The weight of the rear inclined plate $=304.8 \times 9.8066$

$$
=2989.5 \mathrm{~N}
$$

Total weight applied to side wall $=15 \%$ of the total mass of material used $\mathrm{x}$ Acceleration due to gravity

$$
\begin{aligned}
& =0.15 \times 780 \times 9.8066 \\
& =1146.5 \mathrm{~N}
\end{aligned}
$$

Total weight applied to the side wall =total weight applied to heard board.

Total weight applied to chamfer $=24.63 \times 9.8066$

$$
=241.6 \mathrm{~N} \text {. }
$$

\subsection{Boundary condition of three wheel dump body}

The table 4 shows the boundary conditions of fixed support were applied to the base of three wheeled dump body because the body was restricted in the direction of $\mathrm{u}_{\mathrm{x}}, \mathrm{u}_{\mathrm{z}}$ and $\mathrm{u}_{\mathrm{y}}$ are restricted. Due to the body is fully rested on the sub frame. The top hinged pivot points was used for testing the dump body to unloading purpose which having no any type of displacement and also rotating about $r_{y}, r_{z}$ were fixed and $r_{x}$ free. Because of the hinge point is rotating in $X$-axis.

The down hinged pivot points are used to transfer the pressure energy from hydraulic seal equipment to dump a body due to which the body is raised upward. Because the upper end of the body is connected through pivot point. Which have only revolute in X-axis. Finally the down hinged support having a displacement in y-direction, revolute in $\mathrm{X}$-axis. The reaming factors are fixed.

Table 4. Boundary Conditions

\begin{tabular}{|l|c|c|c|c|c|c|}
\hline \multicolumn{1}{|c|}{ Place for dispacement } & $\mathrm{Ux}$ & $\mathrm{Uy}$ & $\mathrm{Uz}$ & $\mathrm{Rx}$ & $\mathrm{Ry}$ & $\mathrm{Rz}$ \\
\hline underframe & 0 & 0 & 0 & 0 & 0 & 0 \\
\hline Top hingh & 0 & 0 & 0 & free & 0 & 0 \\
\hline Bottom hingh & 0 & free & 0 & free & 0 & 0 \\
\hline
\end{tabular}

\section{RESUlts AND DisCuSSION}

To minimize induced stresses in body deformation, material properties are changed to varies components and boundary conditions are applied same to the body. As per material properties dump bodies are divided in to three types and weight of dump body for different types is shown in table 5.

1 aluminium body [7]

2 mild steel body

3 combinations of aluminium and mild steel body

Table 5. Weights Of Individual Bodies

\begin{tabular}{|l|c|}
\hline \multicolumn{1}{|c|}{ Type Of Three Wheeled Dump Body } & Weight (Kg) \\
\hline Mild Steel & 102.6 \\
\hline Aluminum & 36.347 \\
\hline Combination Of Mildsteel And Aluminum & 68.128 \\
\hline
\end{tabular}




\subsection{Deformation results for three types of three wheeled dump bodies}
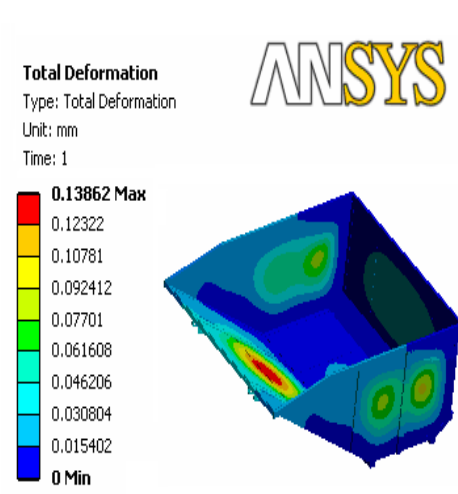

Figure: 7 Total deformations for Mild steel body
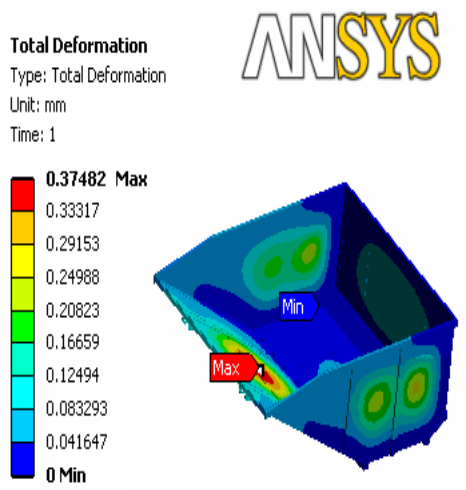

Figure: 8 Total deformations for Aluminium body

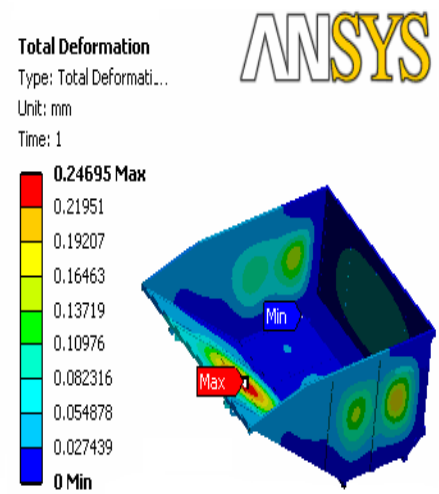

Figure: 9 Total deformations for combination of mild steel Aluminium body

The figure represents the deformation [9] of the body using Workbench ANSYS software. Here the deformation of the mild steel body occurs which is a maximum of $0.13862 \mathrm{~mm}$, which is within allowable deformation limits. This is shown in figure 7 with the red colour region here the deformation of the aluminium body occurs which is a maximum of $0.37482 \mathrm{~mm}$, .which having more deformation as compare to the mild steel dump body. This is also within allowable deformation limits. This is shown in figure 8 with the red colour region. The third body is a combination of mild steel and aluminium alloy, its maximum deformation is $0.24695 \mathrm{~mm}$, which is more deformation as compared to mild steel body and less deformation is compared to aluminium body. This is also within allowable deformation limits. This is shown in figure 9 with red colour region.

\subsection{Stress intensity results for three types of three wheeled dump bodies}
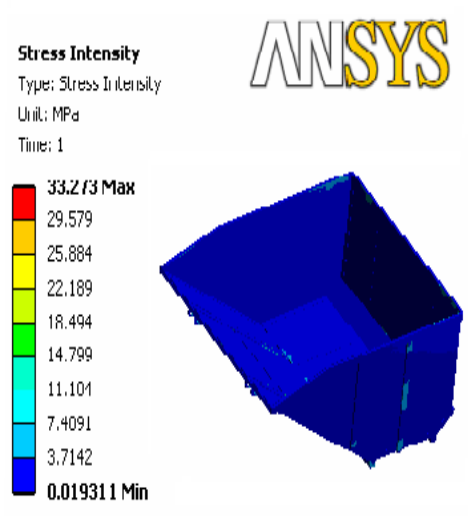

Figure: 10 Stress intensity of Mild steel body

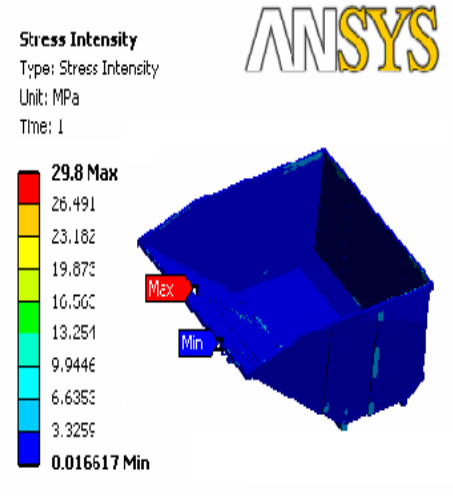

Figure: 11 Stress intensity of Aluminium body

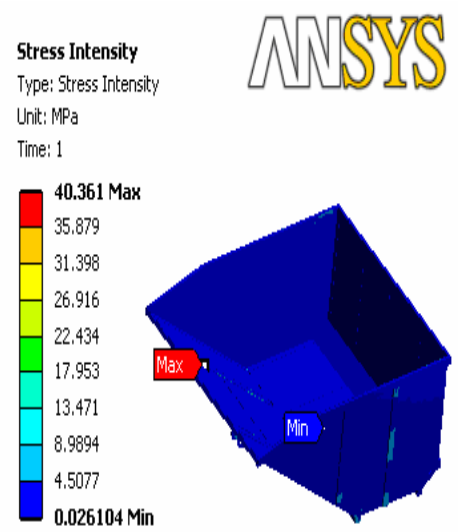

Figure: 12 Stress intensity of mild steel and Aluminium body. 
- The figure represents the stress intensity results of the body using Workbench ANSYS software. Here the stress intensity result of the mild steel body occurs which is a maximum of $33.273 \mathrm{MPa}$, which is within allowable stress limit. This is shown in figure 10 with the red colour region

- $\quad$ Here the stress intensity results of the aluminium body occur which is a maximum of 29.8 $\mathrm{MPa}$, which having less stress intensity results as compare to the mild steel dump body. This is also within allowable stress limit. This is shown in figure 11 with the red colour region.

- The third body is a combination of mild steel and aluminium alloy, its maximum stress intensity is $40.365 \mathrm{MPa}$, which is more stress intensity results as compared to mild steel body and aluminium alloy body. This is also within allowable stresses limit. This is shown in figure 12 with red colour region.

\subsection{Von-Mises stress results for three wheeled dump bodies}

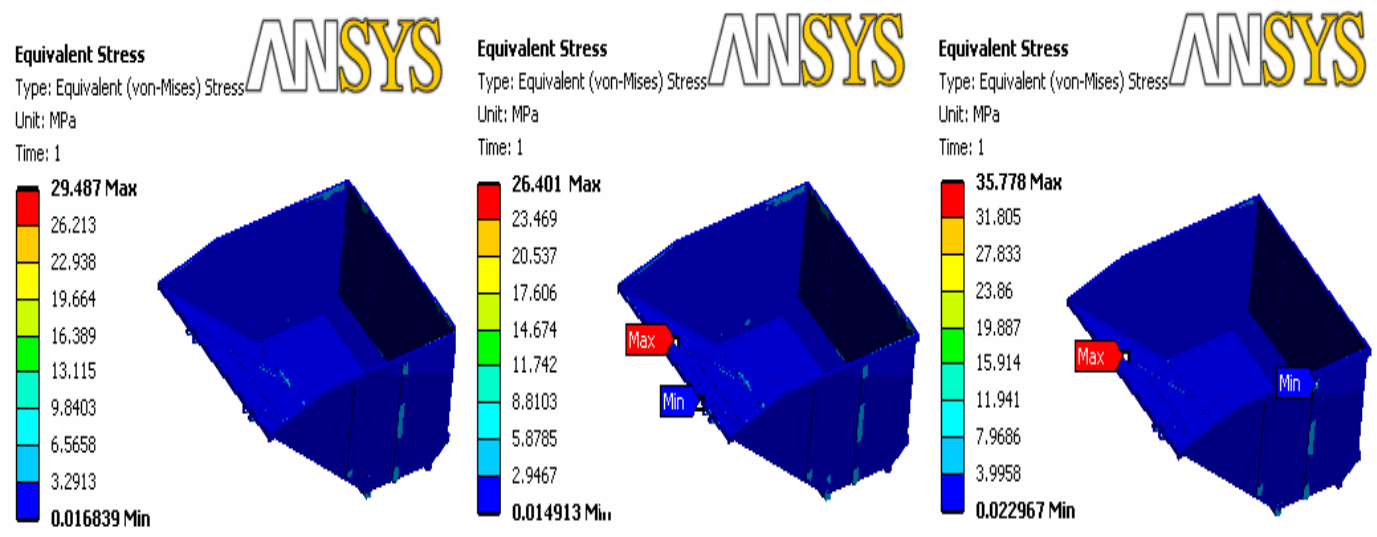

Figure: 13 Stress intensity of Mild steel body
Figure: 14 Stress intensity of Aluminium body
Figure: 15 Stress intensity of mild steel and Aluminium body

- The figure represents the von-Mises stresses results of the body using Workbench ANSYS software. Here the von-Mises stresses results of the mild steel body occur which is a maximum of $29.487 \mathrm{MPa}$, which is within allowable stress limit. This is shown in figure 13 with the red colour region.

- Here the von-Mises stresses results of the aluminium alloy body occurs which is a maximum of $26.401 \mathrm{MPa}$, .which having less von-Mises stresses [10] results as compared to mild steel dump body. This is also within allowable stress limit. This is shown in figure 14 with the red colour region.

- The third body is a combination of mild steel and aluminium alloy, its maximum von-Mises stresses results is $35.778 \mathrm{MPa}$, which is more von-Mises stresses results as compared to mild steel body and aluminium body this is also within allowable stress limit. This is shown in figure 15 with the red colour region.

\section{CONCluSions AND SCOPE OF Future WORK}

The three wheeled dump body is designed by considering various parameters like internal load acts on the body, centre of gravity and required thickness calculations. In this design numbers of standard dimension parts are used to reduce the manufacturing cost of the auto dump body. The standard parts like angular channel, square channel and rectangular stiffeners etc. The total 
assembly model is performed in PRO/E 4.0 CAD Software. Analysis is done by ANSYS11.0 (WORK BENCH.)

The designed body imported to ANSYS WORK BENCH through IGES file by changing material properties of three wheeled dump body three types of analysis are performed and to find a required body.

The mild steel body is analyzed and it has more weight nearly $102.6 \mathrm{kgs}$. The finite element results are within the design limit. But it is not suitable for the wet garbage purpose due to easily effected by corrosion. Aluminium is taken as the second material it has the weight of $36.347 \mathrm{kgs}$. It can be analyzed in finite element results are within the desired limit, but the total cost of manufacturing is high. The third body is taken in combination of two materials the garbage contact material taken as aluminium sheets and the supporting components are mild steel material. The finite element results are within the desired limit as per the capacity of loading, cost of manufacturing, fuel consumption and corrosion resistant. The final body is chosen as the best body for dry and wet garbage purpose.

Since the total analysis is done in static conditions, basing on these results we can follow from Dynamic analysis where the vehicle is not stationary. Transient analysis can also find where sudden loads are applied in the dumper body. Model analysis can also perform to find the frequencies to the mode shapes by applying boundary conditions.

\section{REFERENCES}

[1] Johaan Kraus, "Garbage collection vehicle”, Grant, March 31, 1971, publication number: US3598262 A.

[2] Ali. R, J. L. Hedges, B. Mills, (1986), "Finite element techniques are applied to determine the static properties of and automobile body", , I. M. E. , Proc., Vol. 185, 44/71.

[3] Kiyoshi Miki,(2000) "The outline of a theoretical analysis of bending and torsional vibrations of bodies", , Paper No: 690272.

[4] Curtis. F. Vail, (1993) "F. E. Methods for modeling automatic structure for their static characteristics", Paper No: 740005.

[5] Garrett. T.K (1 Dec. 2002), "The Motor Vehicle", Society of Automotive Engineers,U.S.; 13th Revised edition, Paper No: 1214.

[6] Hutton, David, V., (2004),'Fundamental of Finite Element Analysis”, Mc Graw Hill, New York.

[7] Mauritz Coetzee, (2004) "An innovative aluminum design gives a truck-body manufacturer the competitive edge in the worldwide construction industry".

[8] Robert. J. Melton, (1999) 'Efforts to predict linear static dynamic and non-linear behavior of components and structural systems', , Paper No: 740319.

[9] Willy Peterson, (Ford Motor Co.,)(1999), 'The finite element method for automotive body structural analysis', Paper No: 740319.

[10] R.S Khurmi and J.K Guptha, (1984) “Text books of machine design”. Eurasia Publishing, 1067 pages. 